\title{
Soil and Sediments Microzonation for Evaluation of Site Effects on Earthquake Damages in Mobarakeh, Esfahan, Iran
}

\author{
Khalil Rezaei ${ }^{{ }^{*}}$, Nasibeh Mumsaz ${ }^{2}$, Hasan Hejazi ${ }^{2}$, Reza Sarraf ${ }^{3}$, Susan Norouzi ${ }^{3}$ \\ ${ }^{1}$ Tarbiat Moallem (Kharazmi) University, Tehran, Iran \\ ${ }^{2}$ Azad Islamic University of Khurasgan, Esfahan, Iran \\ ${ }^{3}$ Azad Islamic University of Mobarakeh, Esfahan, Iran \\ Email: *khalil.rezaei@tmu.ac.ir
}

Received June 26, 2012; revised July 27, 2012; accepted August 24, 2012

\begin{abstract}
As an important step in effectively reducing seismic risk and the vulnerability of the city of Mobarakeh to earthquakes, a site effect microzonation Study was conducted. Seismic hazard analysis for a return period of 475 years was carried out. Data from 10 borings was collected and analyzed, geophysical surveys were conducted and seismology and geoelectric measurements taken in more than 17 stations through out the city. The study area was divided into a grid of $500 \times 500 \mathrm{~m}^{2}$ elements and the sub-surface ground conditions were classified into 5 representative geotechnical profiles. Electric resistivity was measured in close to 17 geotechnical boreholes and surface and sub-surface sediments were collected and analyzed. Site response analyses were carried out on each representative profile using 30 different base rock input motions. Distribution maps of site periods and peak ground acceleration and old and new texture buildings through out the city were developed, providing a useful basis for land-use planning in the city.
\end{abstract}

Keywords: Soil; Sediment; Site Effect; Microzonation; Earthquake

\section{Introduction}

Ground shaking and its associated damage to engineered structures can be strongly influenced, not only by source and path effects, but also by surface and sub-surface geological (depth and type of bedrock, underground sediments) and geomorphologic conditions in the vicinity, known as "local site effects". Iran is one of ten countries with most unexpected events in the world. Evidence of this can be found in two major seismic events in Iran in the past two decades - 1990 Manjil-Rudbar and the 2003 Bam earthquakes - that resulted in a large number of casualties. Although these cities had comparatively low populations, the lack of suitable development and earth quake risk management led to high human and physical costs [1]. These tragedies prompted the local researchers and government to implement earthquake risk mitigation measures, including seismic hazard zonation and microzonation of vulnerable cities, to facilitate urban planning. Also, 96\% of cities are located on alluvial sediments around Iran and such researches are necessary for them.

The industrial and economic of Mobarakeh city, with huge and important factories such as steel complex, is situated $60 \mathrm{~km}$ southwest of Esfahan in center of Iran

${ }^{*}$ Corresponding author.
(Figure 1) and covers an area of approximately $23 \mathrm{~km}^{2}$. In the past two decades, it has experienced a sizeable increase in population.

In previous studies $[1,2]$ carried out a soil and sediment quality microzonation study of Bam city from seismic hazard point of view. They estimated the horizontal peak acceleration for basement rock with out considering soil types, based on the tectonics and seismicity of the Kerman province using the Cornell approach. They showed that the seismicity of Bam is not only affected by well-known minor fault under the cities of Bam and Baravat, but also by a major and active fault under the city itself. Also, Kamalian et al., (2008) [3] performed a completely similar project in Qom city. These results prompted the government to implement immediate measures to prevent the kind of destruction seen in previous earthquakes in most of cities in Iran. As a new research, the Islamic Azad University of Mobarakeh carried out a site effect microzonation study of this city in 2010. The goals of this investigation were to prepare guide lines for further land-use planning and to provide data for future studies of existing urban systems and seismic rehabilitation processes. The geotechnical aspects of the program were divided into two parts: site effects estimation and geotechnical hazards evaluation. 


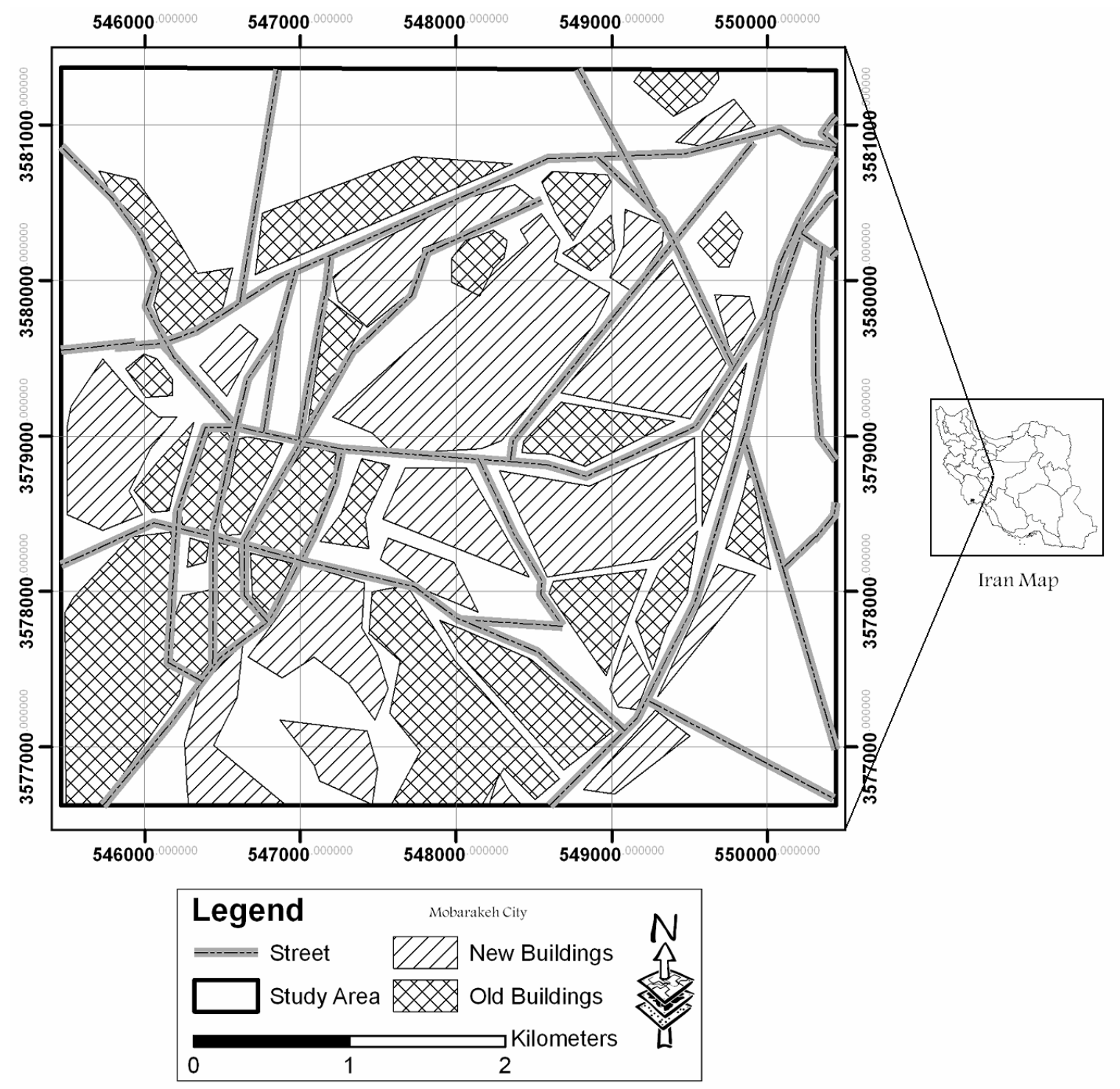

Figure 1. Location of Mobarakeh and study area limits.

This paper presents the major results obtained during the site effect microzonation study.

\section{Methodology}

The methodology of soil and sediment quality and site effect microzonation adopted in this study falls into the category of Grade- 3 zoning methods of the Japanese TC4 Zoning Manual, (1999) [4-6] and previous experiences of Authors. After dividing the city into a grid of $500 \times 500$ $\mathrm{m}^{2}$, the following steps were taken:

- Preparation of a seismic hazard map of the study area for a return period of 475 years;

- Gathering and investigation of the existent geological, geotechnical, sedimentological and geophysical data of the study area, including field observations and Sampling and aerial photo studies;
- Conducting complementary geophysical investigation, as well as geoelectrical and seismology measurements and sedimentological studies, through out the study area;

- Several experimental analyses on soil and sediment samples in TMU university laboratory;

- Preparation of representative geotechnical profiles of the city based on the geological, sedimentological, geotechnical, geophysical and geoelectrical data;

- Estimation of strong ground motion characteristics using one-dimensional site response analysis of the representative geotechnical profiles;

- Preparation of the surface and sub-surface grain size maps of the study area in the Geography Information System (GIS) media and geological cross sections in $\mathrm{N}-\mathrm{S}$ and $\mathrm{W}-\mathrm{E}$ directions; 
- Preparation of the final site periods and Peak Ground Acceleration (PGA) maps of the study area in GIS.

\section{General Geology}

From a geomorphologic point of view, the city of Mobarakeh is situated on a flat area of Quaternary deposits. The northern part of the city is constructed at the piedmont of a chain of medium latitude mountains with a series folds. The predominant rock formations are K4 and $\mathrm{K} 7$ cretaceous units, consisting mainly of limestone and sandstone. To the south and east, the city is surrounded by very low and sparse hills (Figure 2). Tec- tonic situation of area is very active that will describe in seismicity section. Also, there are more than 200 wells with high depths for agriculture and industrial applications using ground water. Water table level in this area fluctuates between $35 \mathrm{~m}$ to $50 \mathrm{~m}$.

Based on previous geoelectrical profiling [7], these rock units are largely covered with deep (more than 200 m) Quaternary deposits at the city site. The Quarternary deposits are both ancient (Q1) and recent (Q2) alluvial terraces, as shown in Figure 2, with outcroppings on the center and south parts of Mobarakeh and are mainly loose clayey-silty and sandy layers with inter layers of

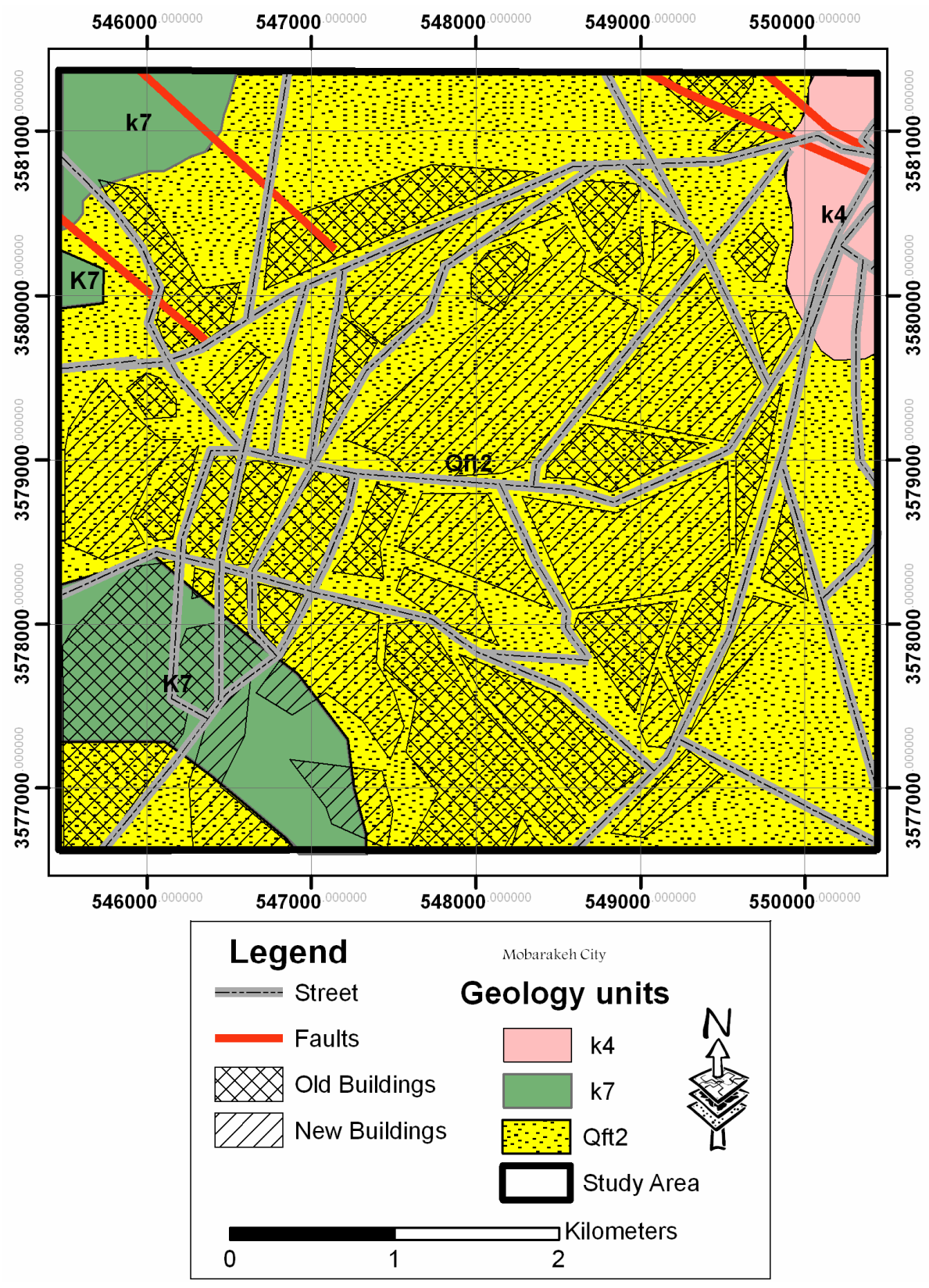

Figure 2. Geologic map of study area [10]. 
coarse grained deposits. The terraces in the studied area are covered by relatively shallow soft silty clay (ML-CL) and clean clay (CL), presented as Qft, which were mostly deposited by floods during the Holocene period. The thickness of alluvial deposits increases from southwest to northeast of the city and the soil grains become finer toward center of plain. The ground water level has a depth of less than $25 \mathrm{~m}$ in north and northeast of the city, deepens to ward the south and finally reaches a depth of a bout $34 \mathrm{~m}$, which constitutes a free aquifer in the Quaternary deposits of the Mobarakeh alluvial. The construction of the waste water dams of steel complex have affected the ground water level and its quality in the recent years, deepening it from levels measured 40 years ago $[7,8]$.

\section{Seismicity and Seismic Hazard}

Mobarakeh is situated between the Zagros and central Iran seismotectonic units. Central Iran is not a linear seismic zone. It is characterized by scattered seismic activity with large magnitude earthquakes, long recurrence periods and seismic gaps along several Quaternary faults. Figure 3 shows the minor active faults around Mobarakeh. Several researchers published the characteristics map of active faults around Mobarakeh [7]. The most important faults outside the city are the Zagros and Qom-Zefreh faults having strike slip mechanisms and reverse components $[6,9]$. These faults are the most important active Quaternary faults in the area, having caused surface displacements in the Holocene or Pleisto- cene period. The lengths of these two Quaternary faults are about 500 and $290 \mathrm{~km}$ and their maximum estimated moment magnitudes are 6.9 and 6.1 , respectively. The focal mechanisms of earthquakes are mostly reverse with left lateral strike slip components. The shocks in central Iran are generally shallow and are usually associated with surface faulting. The only historical earthquake close to Mobarakeh was the 1791 earthquake with a magnitude of 4.9 (Figure 3). A few instrumentally located events of small magnitude have been observed around Mobarakeh. The instrumental seismicity shows that at least 6 earthquakes have occurred with in a $100 \mathrm{~km}$ radius of Mobarakeh with magnitudes of less than 5.0.

This study presents a Probabilistic Seismic Hazard Analysis (PSHA) based on the tectonic position and seismicity of the Mobarakeh region. The PSHA is based on the Cornell approach. Area sources were identified on the basis of geological and seismological studies (Figure 4). For each source zone, seismicity parameters have been estimated after omitting foreshocks and aftershocks from the catalogue. Each source zone is characterized by an earthquake probability distribution. A maximum or upper bound earthquake was chosen for each source zone representing the maximum event to be considered. The seismicity parameters, including the Gutenberg-Richter parameter $(\beta)$, maximum possible earthquake (Mmax) and mean activity rate $(\lambda)$ for each seismic zone used for the PSHA are given in Table 1.The depth of the earthquakes was considered as $10 \mathrm{~km}$ based on the depth of strong-to-large earthquakes in Iran.

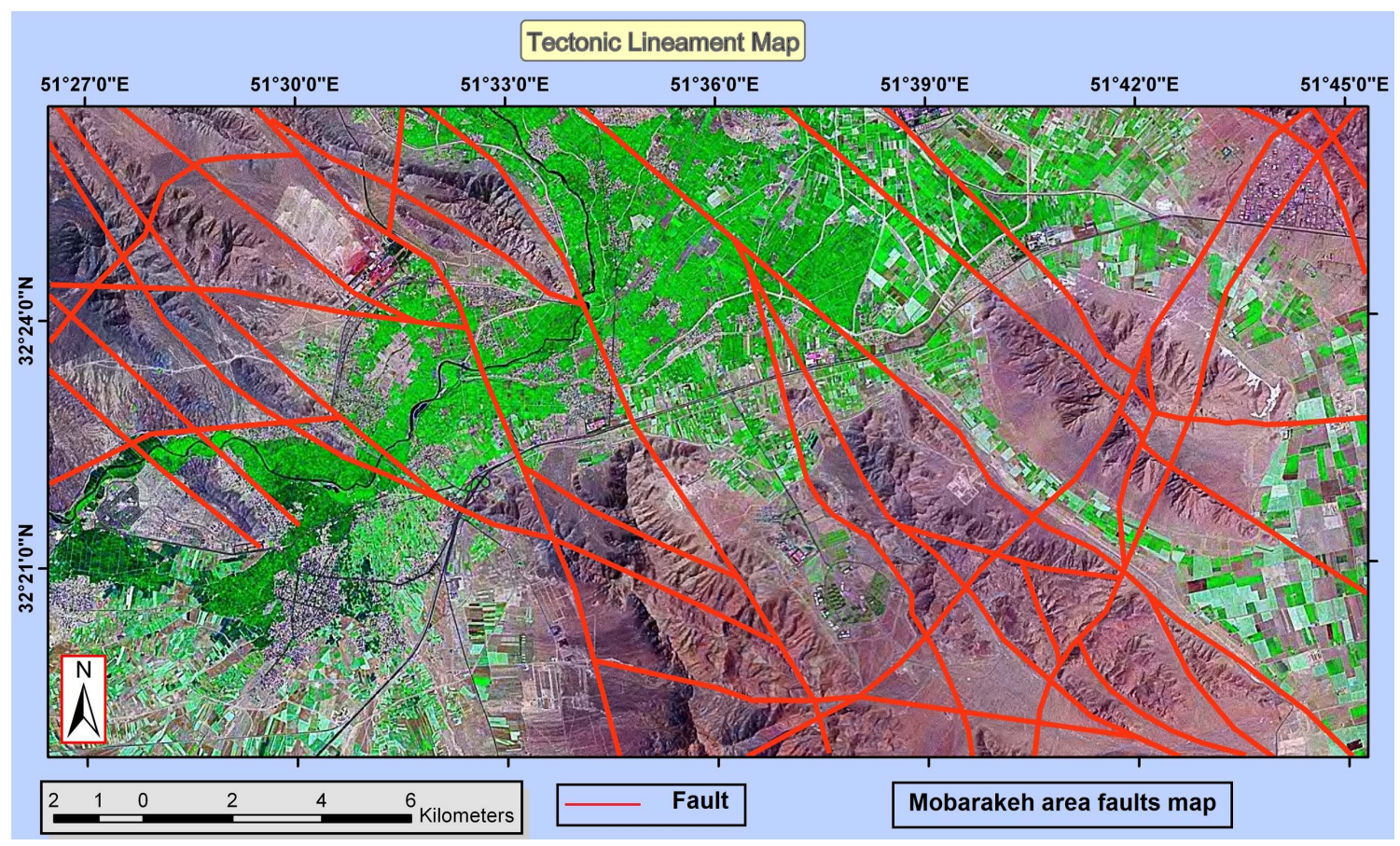

Figure 3. Minor active faults around Mobarakeh city [7]. 


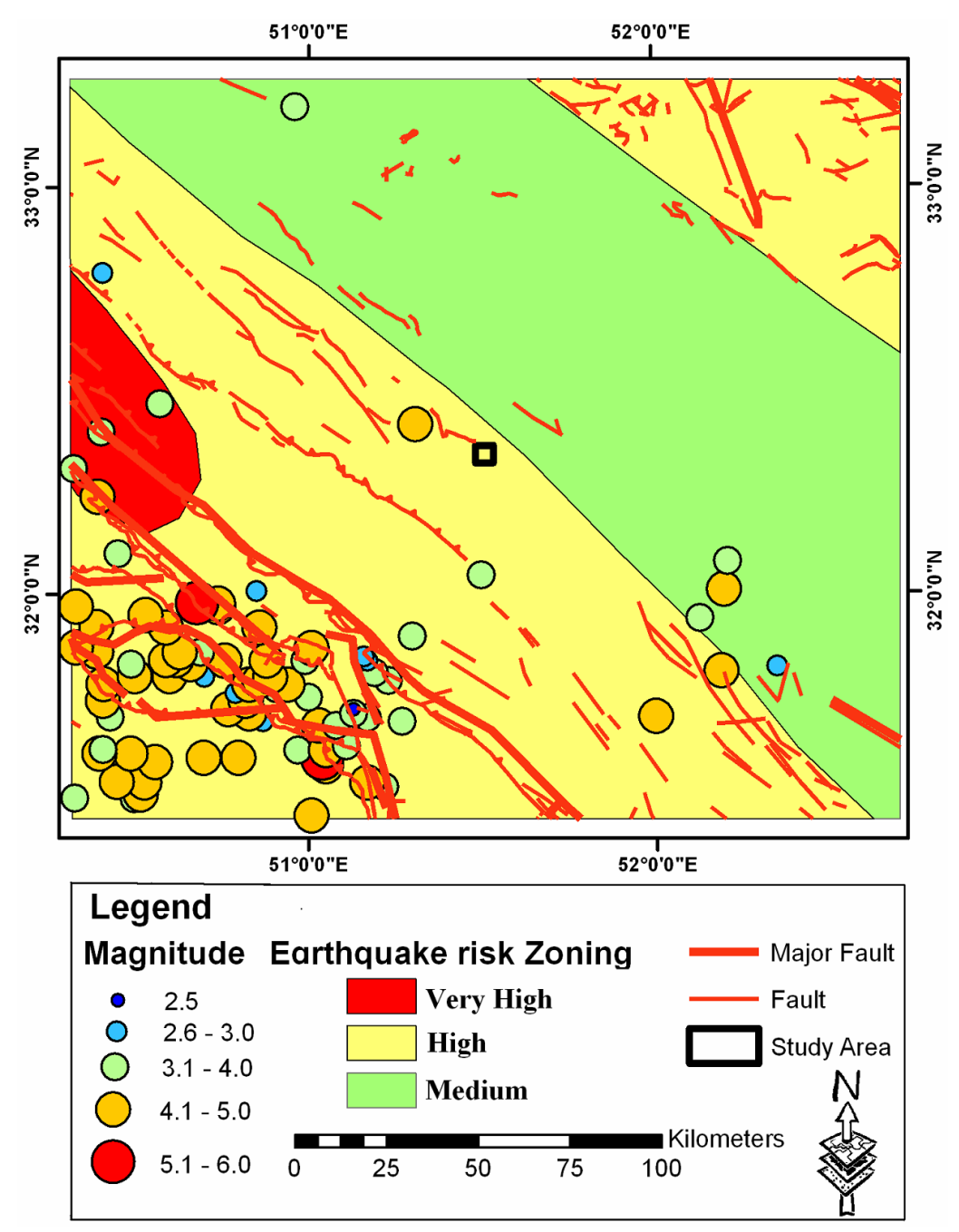

Figure 4. Seismic events and risk zoning in study region.

Table 1. Parameters of seismic zones used for the PSHA.

\begin{tabular}{cccc}
\hline Zone & $\beta$ & M max & $\lambda(4.5)$ \\
\hline Z1 & 1.64 & 7.9 & 0.54 \\
Z2 & 1.60 & 7.8 & 0.52 \\
Z3 & 1.40 & 7.7 & 0.058 \\
Z4 & 1.22 & 7.4 & 0.059 \\
Z5 & 1.58 & 6.8 & 0.07 \\
Z6 & 1.68 & 6.5 & 0.06 \\
Z7 & 1.48 & 7.1 & 0.12 \\
Z8 & 2.23 & 7.6 & 0.59 \\
\hline
\end{tabular}

A reliable assessment of seismic hazard in a region requires knowledge and understanding of both the seismicity and the attenuation of strong ground motion. Some of the larger uncertainties in earthquake hazard analysis are caused by uncertainties in seismic wave at- tenuation. Several studies have been carried out to obtain attenuation relationships of peak ground accelerations for different regions of the world. The use of different data bases and published empirical attenuation relations for peak ground acceleration brings a bout widely varying results. Thus, it becomes difficult to select a relationship that can be considered appropriate for a specific application. Furthermore, the use of a particular relationship for an area with different geological and tectonic features may lead to results that differ significantly from the actual values. Therefore, three proper attenuation relationships proposed by Boore et al. (1997), Zare (1999), and Campbell and Bozorgnia (2003) have been considered $[2,7,8]$. The attenuation relation given by Zare (1999) [2] is based on the Iranian strong ground motion data. Those introduced by Campbell and Bozorgnia (2003) and Boore et al. (1997) are observed to be more similar to measured peak ground acceleration in Iran [7-9]. All three attenuation relationships were used and a logic tree scheme with equal weight was applied. The effects of earthquakes of 
different sizes, occurring at different locations in different earthquake sources for different probabilities of occurrence were integrated into one curve that shows the probability of exceeding different levels of ground motion at the site during a specified period of time. Figure 5 shows the distribution map of Peak Rock Acceleration (PRA) in Mobarakeh for a return period of 475 years. As can be seen, the PRA value varies from 0.31 to $0.39 \mathrm{~g}$, mostly due to data from the Zagros and Qom-Zefreh faults.

\section{Geotechnical Aspects of Mobarakeh}

Although most available reports on geotechnical site investigations Conducted by national and local govern- ments and public corporations were collected but these comprised only 10 boreholes from 7 stations having limited depth (usually less than $60 \mathrm{~m}$ ) and being unequally distributed in the investigated area. To overcome the problem of insufficiency of data, complementary field investigations were designed and conducted. Numerous locations in the study area were selected as being topologically, geologically and sedimentological representative sites for conducting the complementary field investigations. These included seismic refraction surveys at 19 stations, geo-electrical profiling at 17 stations and geological surveys at 56 stations. Figure 6 presents the locations of the existing geological and geotechnical data as well as those of the complementary geophysical investigations.

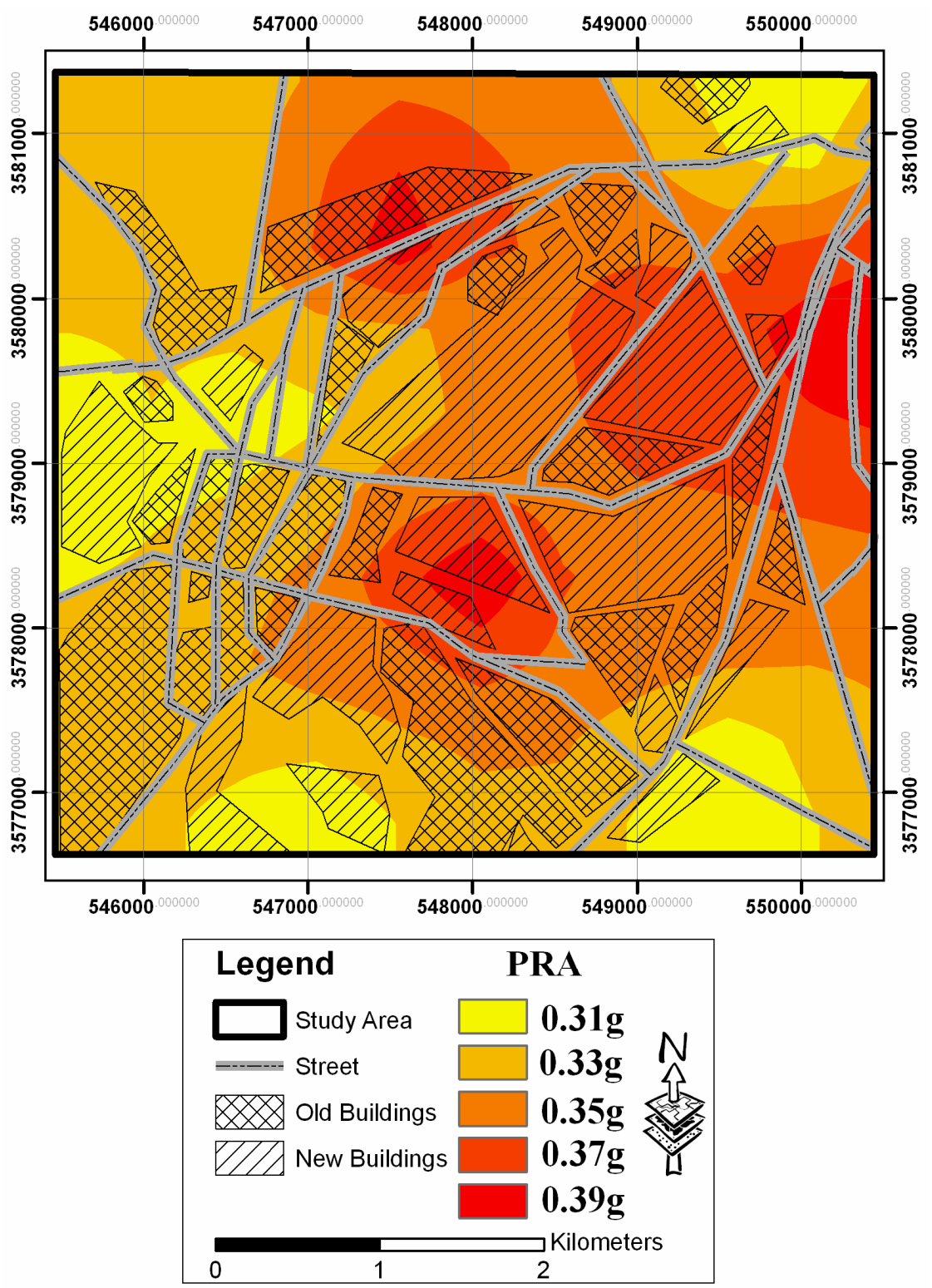

Figure 5. Distribution map of PRA for a return period of 475 years. 

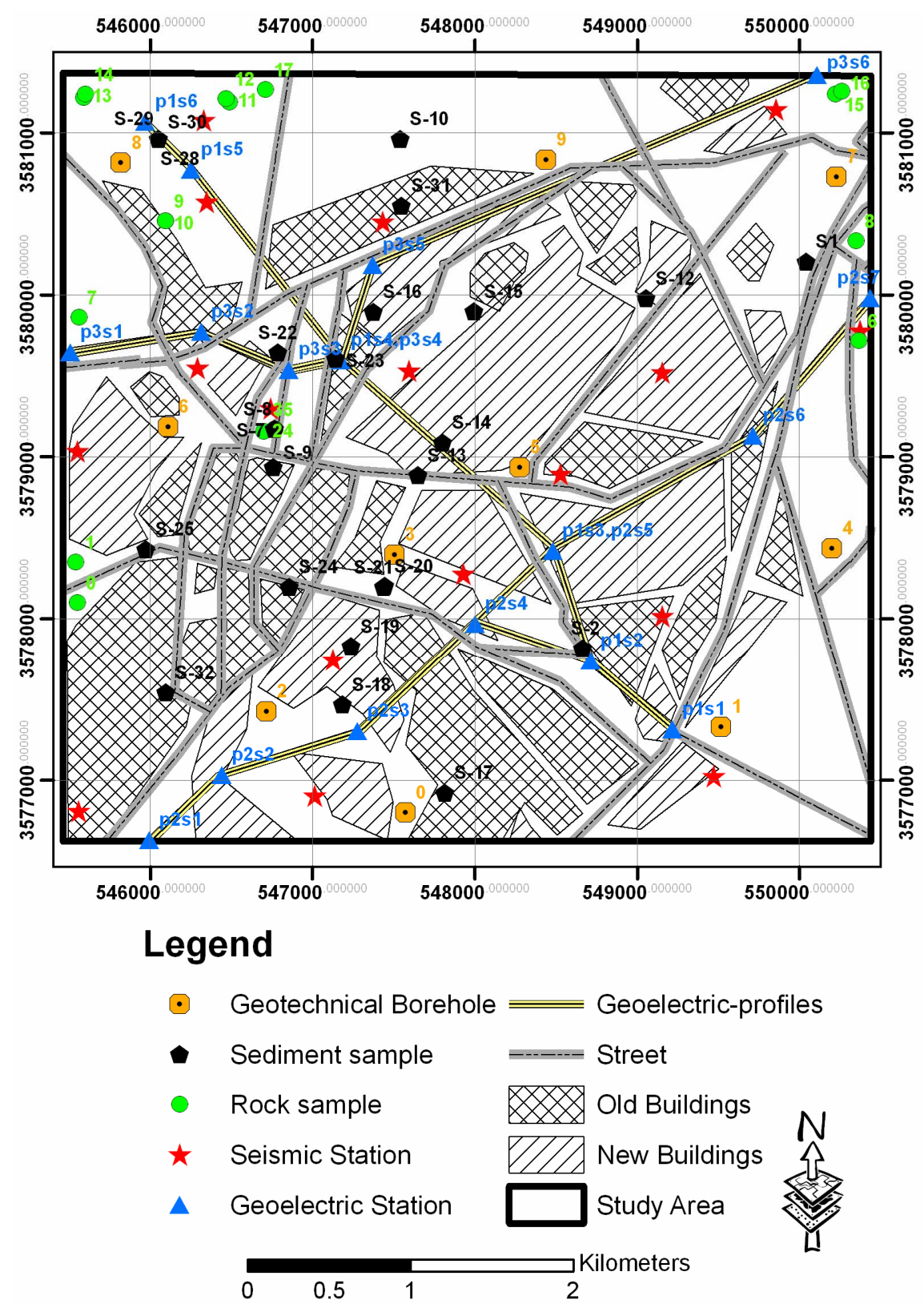

Figure 6. Geotechnical and complementary geophysical and geological stations.

For the purpose of the study, seismic bedrock has been defined as rock-like media with shear wave velocities of over $700-800 \mathrm{~m} / \mathrm{s}$ [4,11-13], which is suitable for ordinary low to medium-rise buildings [3]. Distribution maps of sub-surface sediments (Figure 7), depth of the seismic bedrock (Figure 8), as well as some geotechnical sections (Figure 9) were compiled using the accumulated data. The maps give clear perspectives on the variability of soil conditions through out the study area. The ground conditions of the study were thus categorized according to soil type, layer thickness and depth of seismic bed rock into three distinct zones (Figure 10):

- Zone 1: south and some parts of southwest of Moba- rakeh that is significantly different, with dominant Clayey Layers (CL) to a considerable depth. In this zone, the average shear wave velocity is less than 300 $\mathrm{m} / \mathrm{s}$ and the depth of seismic bedrock exceeds $90 \mathrm{~m}$.

- Zone 2: rock outcrops covering the southwest and northeast mountainous regions and granular coarsegrained alluviums (GP, GW) in central parts of study area. In this zone, low to medium dense sub layers do not exist to near zero, the average shear wave velocity is over $700-800 \mathrm{~m} / \mathrm{s}$.

- Zone 3: granular finer grained alluviums (SM, SW, SP) which cover most parts of the central plain and southwest and northeast edges. In this zone, low to 
medium dense sub layers have no considerable thicknesses, the depth of seismic bedrock varies from 20 to $50 \mathrm{~m}$ and the average shear wave velocity varies from 350 to $500 \mathrm{~m} / \mathrm{s}$. Moving from east to west and from north to south on the plain, the alluvium grain sizes decrease and fine grained soil layers (SM, ML, SC) become dominant (Figure 9). Although some parts of the plain are covered by $2-10 \mathrm{~m}$ of alternating surface clayey and non-clayey sub layers, most parts of the plain consist solely of non-clayey sandy and silty sub layers (SM, ML) that change to gravely/sandy sub layers (GP, GW, SP, SW). To the northwest of the plain, the thicknesses of low to medium dense sub layers and the depth of seismic bed rock increase and the average shear wave velocity decreases. Some parts of the plain form a transition zone between Zone 3 and adjacent Zones 1 and 2. The soil conditions of the zones were classified into several representative geotechnical profiles by considering their combinations of soil type, layer thickness, shear wave velocity and depth of seismic bedrock (Figure 10). Figure 11 show samples of representative geological outcrops and cross sections and Figure $\mathbf{1 2}$ show distribution map of thickness of soil and sediments. Considering information currently available on the underlying structure of Mobarakeh, one possible explanation is the existence of a deeper impedance contrast caused by the Quaternary sediments underlying the surface soil layers and resting at a depth of $100-150 \mathrm{~m}$ from the ground surface on hard geological bed rock from the cretaceous limestone formations having marked differences in elastic properties. The results of deep down-hole and geo-electrical profiles support this. Another possible explanation is the effect of interaction of the surrounding mountain regions with the $3 \mathrm{D}$ basin structure.

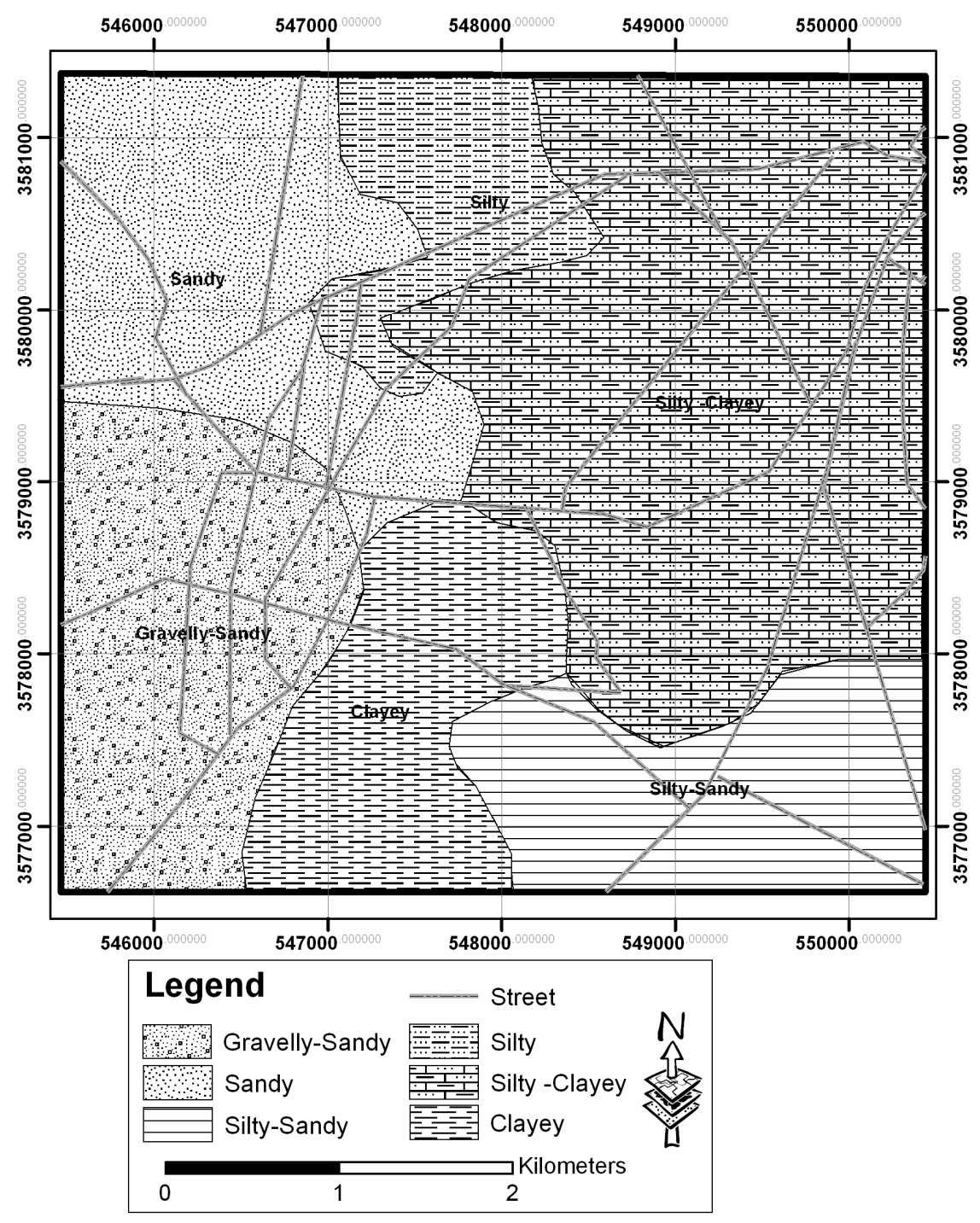

Figure 7. Distribution map of shallow sub-surface sediments. 

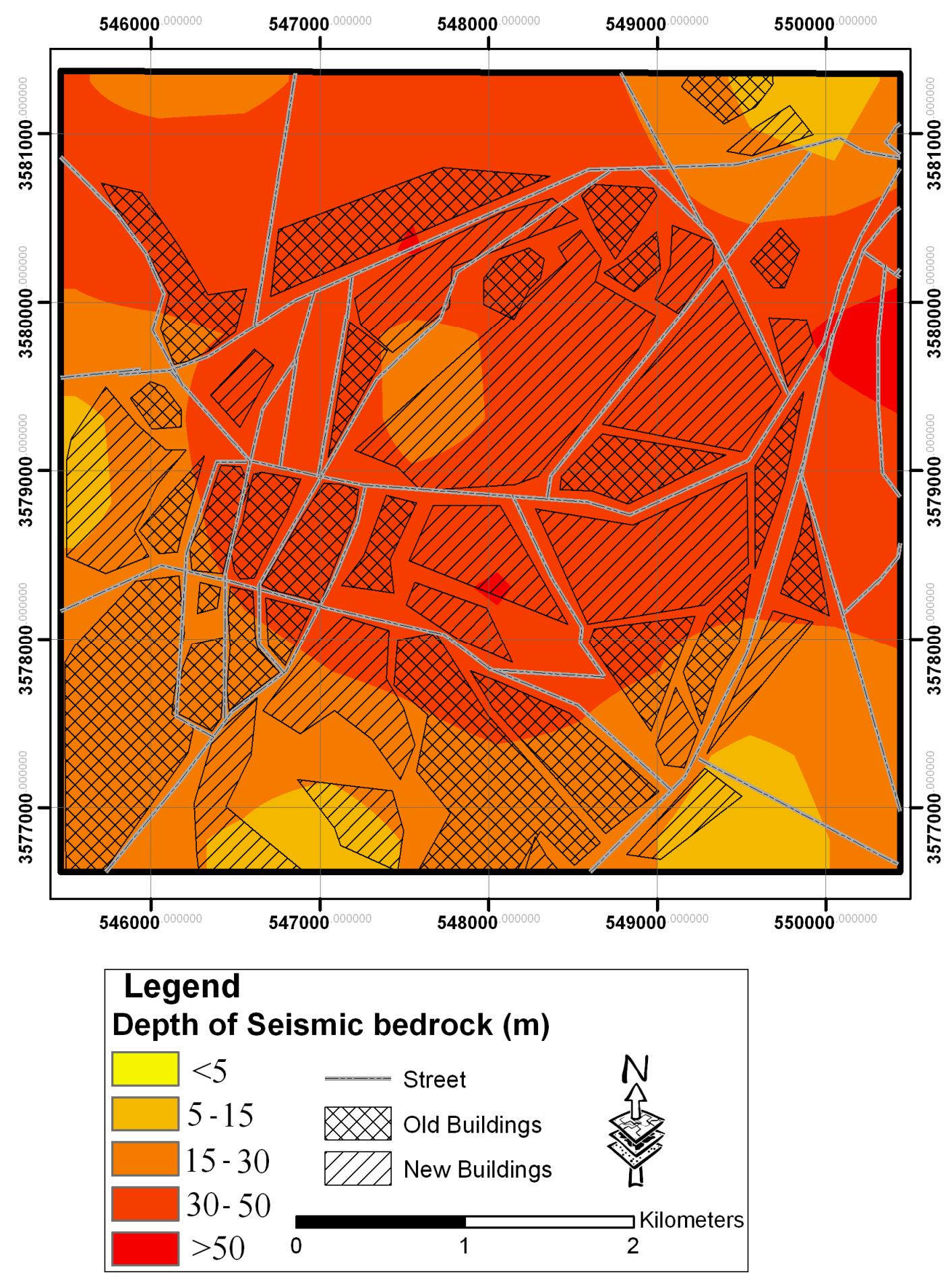

Figure 8. Distribution map of depth of seismic bed rock.

\section{Site Response Analysis}

Non-linear site response analysis was carried out to evaluate the site response of each of the representative geotechnical profiles to the 475 year seismic induced bed rock input motion. The SHAKE program [14] was used to model the site as a one-dimensional system of hori- zontal, homo-generous and isotropic soil layers consistent with actual ground conditions in most of the city where the ground surface and surface soil layers are either virtually horizontal or slope gently. The well-known shear modulus-strain and damping ratio-strain relations proposed by [15] for sand and clays were used in the analysis. Since there are no recorded bed rock strong 

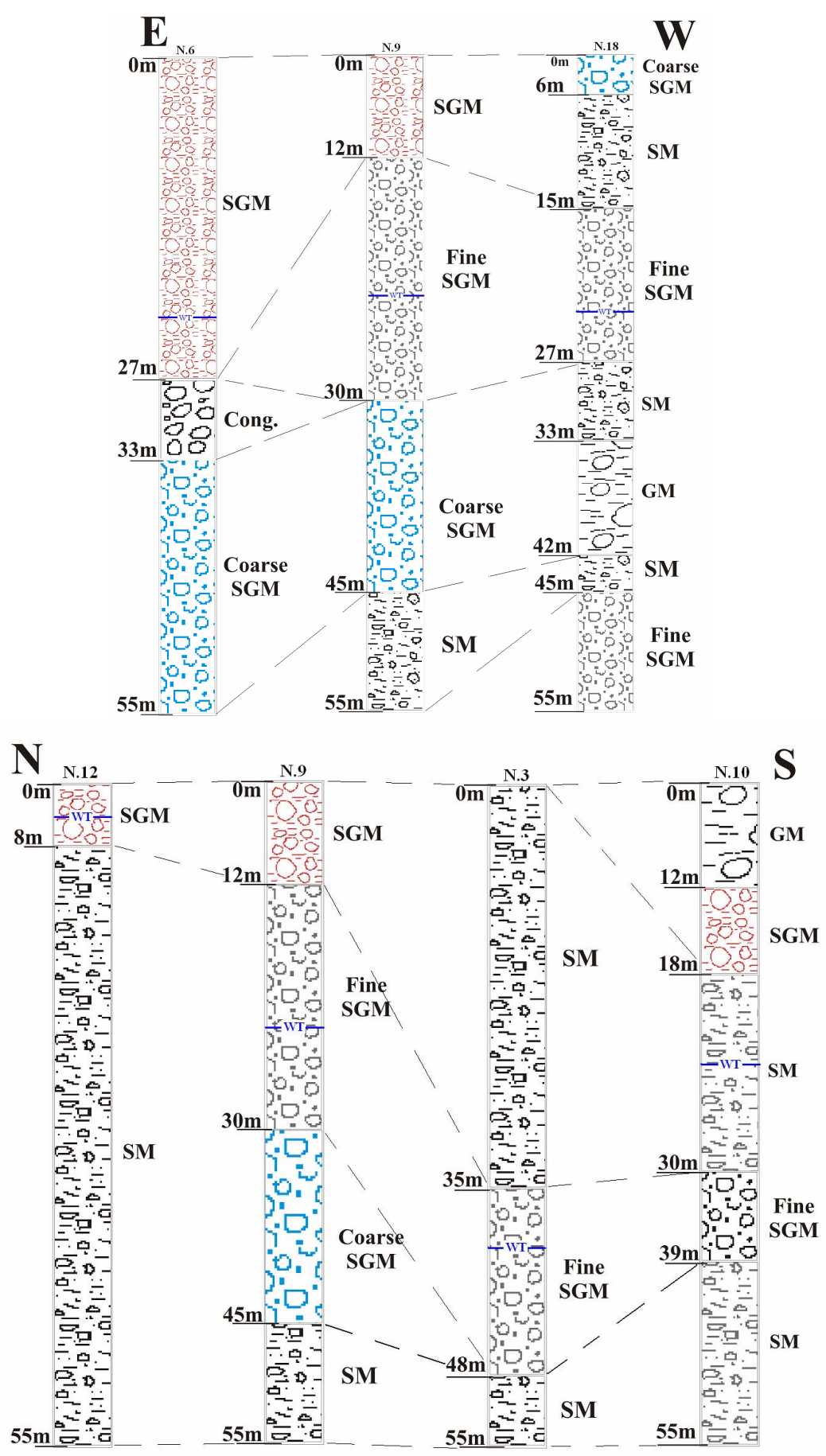

Figure 9. Geotechnical section W-E and N-S directions.

motion time histories for Mobarakeh city, thirty proper Earthquake time histories were selected from available national and international data bases (Table 2) [16,17].

The selected ground motion records were recorded during earthquakes with approximately the same magnitudes (6.0 to 7.5 ) and distances (7 to $60 \mathrm{~km}$ ), as estimated by deterministic approaches for controlling for earthquakes of well-defined seismic sources affecting the study area. Other factors such as the site condition (rocky sites) and style-of-faulting (reverse or strike slip) were also considered [16,18]. All selected acceleration time histories were normalized to the 475 year PRA estimated by PSHA [18]. For each grid element, strong ground motion characteristics including natural site period, dynamic site period, and PGA, were computed by subjecting their representative geotechnical profiles to the normalized 475 


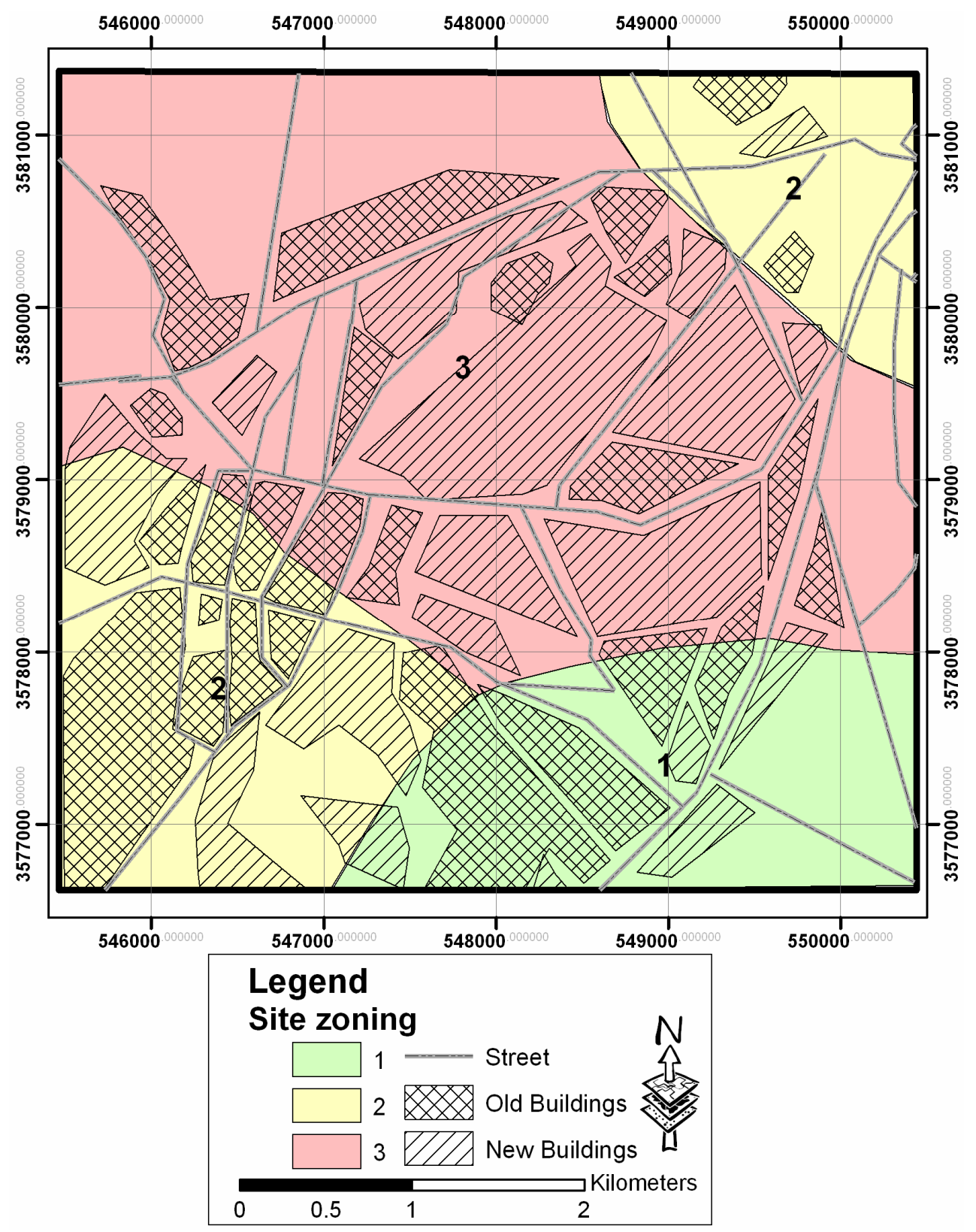

Figure 10. Distribution map of site types.

year bed rock input motions. Once the average results were obtained for each grid element, microzonation maps of the city were created showing the distribution of site amplification characteristics and PGA values through out the study area.

Figure 13 illustrates the distribution of the natural site period (TN) through out the city. Most parts of the city have medium natural site periods of between 0.4 and $0.8 \mathrm{~s}$. Only the south and southeastern part covered by alluviums with low stiffness and considerable thickness, has low natural site periods less than 0.4 s. Figure 14 presents the distribution of the dynamic (non-linear) site periods (TD) through out the city. A comparison of Fig- ures 13 and 14 demonstrates that, as expected, the dynamic site periods are higher than the natural site periods because of the shear modulus reduction caused by the soil's non-linear behavior during 475 year strong earthquakes. Most parts of Mobarakeh have medium dynamic site periods of between $0.4 \mathrm{~s}$ and $0.8 \mathrm{~s}$, except for some parts in the south and southeast of the city, where the thickness of medium dense sub soils and the depth of seismic bed rock increase, which have low dynamic site periods of less than $0.4 \mathrm{~s}$. The west half of study area has high dynamic site periods of more than $0.8 \mathrm{~s}$.

Figure 15 shows the distribution of the 475 year return period PGA through out the Mobarakeh city. The PGA 

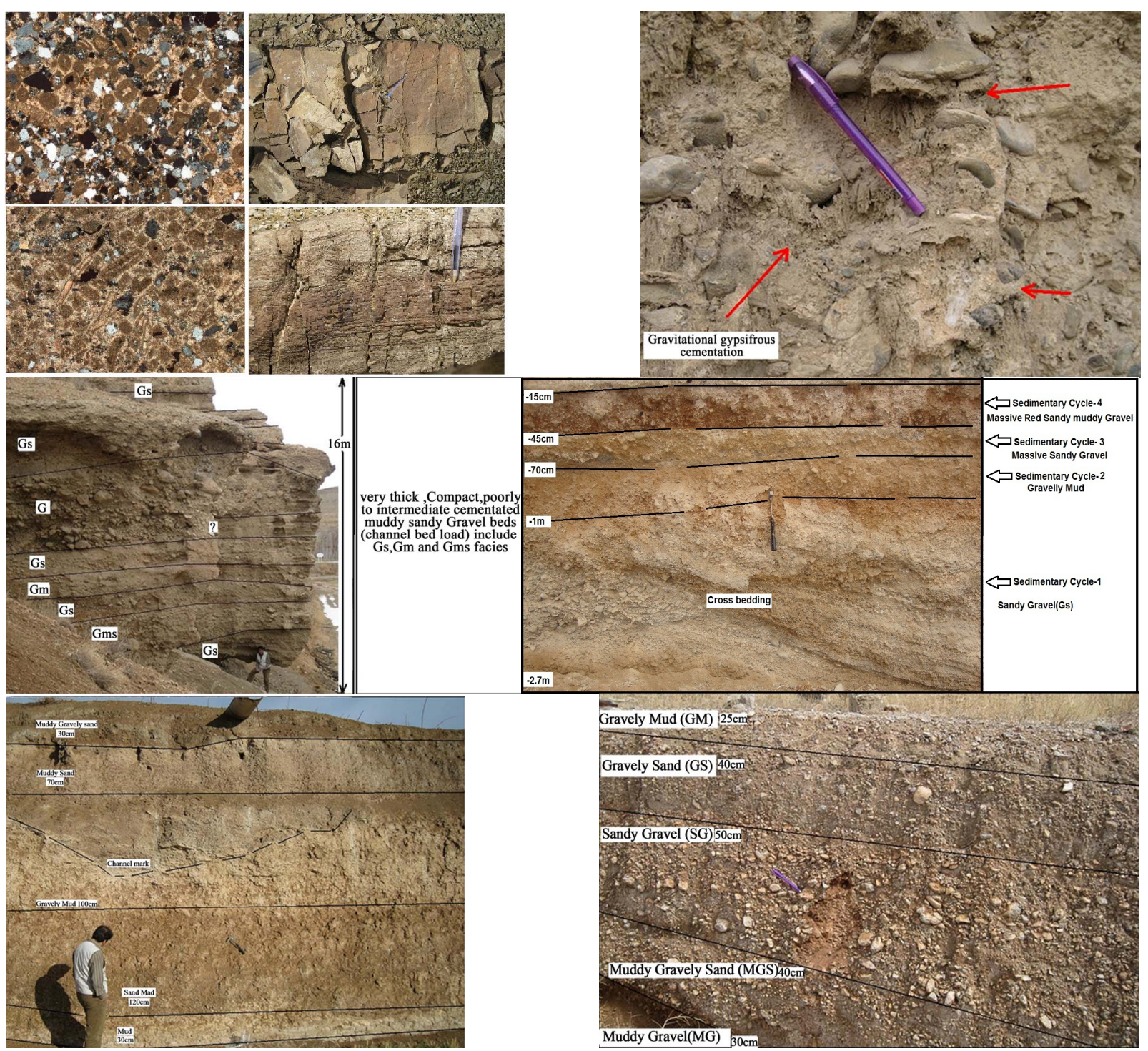

Figure 11. Samples of representative geological outcrops and cross sections.

values vary from $0.3 \mathrm{~g}$ to more than $0.6 \mathrm{~g}$. In GIS media, almost $35 \%$ of the grid elements exhibit PGA values of 0.45 to $0.5 \mathrm{~g}$. Only $9 \%$ of them experience PGA values of about $0.3 \mathrm{~g}$ and approximately $18 \%$ exhibit PGA values of more than $0.6 \mathrm{~g}$. The dense granular alluviums in east of Mobarakeh and the mountainous rocky sites in the east of the city experience the lowest PGA values because either their amplification potential is negligible or their PRA values are the lowest. The alluviums covering the center part of the city and the west and northeast borders of the plain, in particular, experience higher PGA values because oft heir considerable amplification potential caused by low to medium dense soil layers.

\section{Conclusion}

This paper presents the most important features of soil and quality and site effect microzonation studies of Mo- barakeh. Evaluations of the ground motion characteristic are based on seismic risk assessment of the region for a return period of 475 years, and on geophysical (geoelectrical and seismology) measurements and one-dimensional non-linear site response analyses of the geotechnical profiles representing the geotechnical model of the city. It was found that two active or potentially active Quaternary faults with distinct evidence of surface displacements with in Holocene or Pleistocene times lay with in the city. This implies the necessity of considering surface fault-rupture hazard as well as other near field effects in planning future construction in these neighborhoods. It may be attributed to the 3D basin effects or to the presence of thick Quaternary sediments (with shear wave velocity of more than $800 \mathrm{~m} / \mathrm{s}$ ) resting at a depth of $100-150 \mathrm{~m}$ from the ground surface on hard rock from the cretaceous limestone formations. In almost half of the 


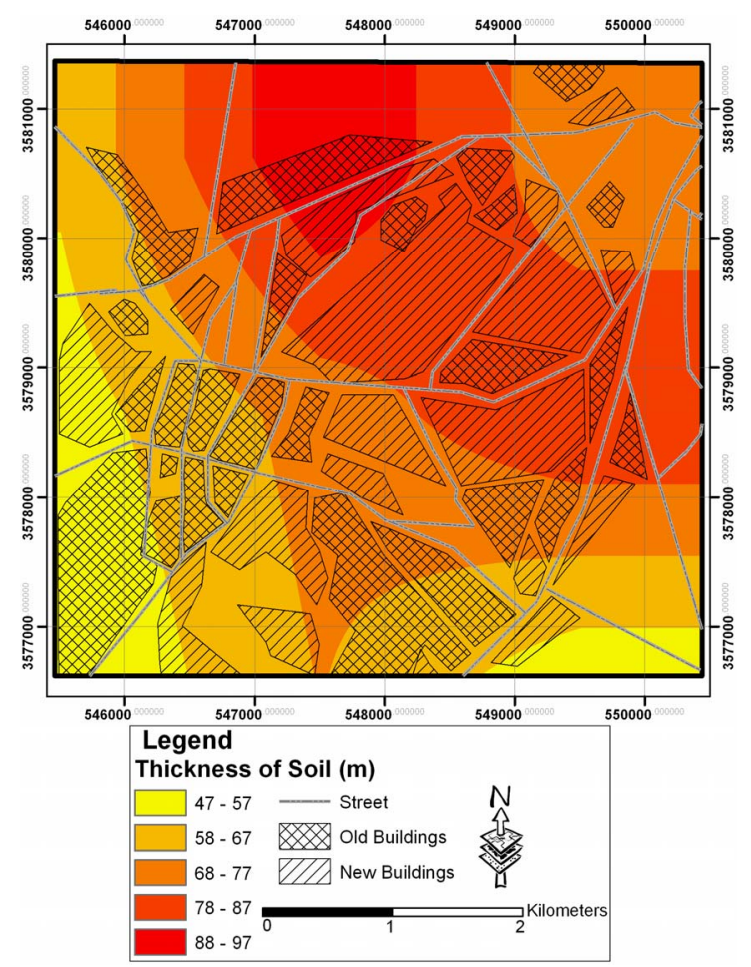

Figure 12. Distribution of Sediment thickness trough out Mobarakeh.

Table 2. Specification of selected accelerograms for site response analysis.

\begin{tabular}{|c|c|c|c|c|c|}
\hline No & Earthquake & Mechanism & Magnitude & Distance & PGA (g) \\
\hline 1 & San Fernando-1971 & Reverse & 6.6 & 23.5 & 0.16 \\
\hline 2 & San Fernando-1971 & Reverse & 6.6 & 23.5 & 0.13 \\
\hline 3 & Vendic, Iran-1976 & Strike slip & 6.4 & 10 & 0.17 \\
\hline 4 & Vendic, Iran-1976 & Strike slip & 6.4 & 10 & 0.18 \\
\hline 5 & Naghan, Iran-1977 & Reverse & 6.1 & 7 & 0.87 \\
\hline 6 & Naghan, Iran-1977 & Reverse & 6.1 & 7 & 0.57 \\
\hline 7 & Tabas, Iran-1978 & Reverse & 7.4 & 45 & 0.11 \\
\hline 8 & Tabas, Iran-1978 & Reverse & 7.4 & 45 & 0.09 \\
\hline 9 & N.PalmSprings-1986 & Reverse oblique & 6.0 & 45.6 & 0.10 \\
\hline 10 & N. Palm Springs-1986 & Reverse oblique & 6.0 & 45.6 & 0.13 \\
\hline 11 & N. Palm Springs-1986 & Reverse oblique & 6.0 & 7.3 & 0.49 \\
\hline 12 & N. Palm Springs-1986 & Reverse oblique & 6.0 & 7.3 & 0.61 \\
\hline 13 & Northridge-1994 & Reverse & 6.7 & 26.8 & 0.17 \\
\hline 14 & Northridge-1994 & Reverse & 6.7 & 26.8 & 0.22 \\
\hline 15 & Northridge-1994 & Reverse & 6.7 & 36.1 & 0.23 \\
\hline 16 & Northridge-1994 & Reverse & 6.7 & 36.1 & 0.13 \\
\hline 17 & Northridge-1994 & Reverse & 6.7 & 8.2 & 0.30 \\
\hline 18 & Northridge-1994 & Reverse & 6.7 & 8.2 & 0.43 \\
\hline 19 & Duzce, Turkey-1999 & Strike slip & 7.1 & 8.2 & 0.51 \\
\hline 20 & Duzce, Turkey-1999 & Strike slip & 7.1 & 8.2 & 0.97 \\
\hline 21 & Duzce, Turkey-1999 & Strike slip & 7.1 & 8.5 & 0.13 \\
\hline 22 & Duzce, Turkey-1999 & Strike slip & 7.1 & 8.5 & 0.15 \\
\hline 23 & Duzce, Turkey-1999 & Strike slip & 7.1 & 27 & 0.05 \\
\hline 24 & Duzce, Turkey-1999 & Strike slip & 7.1 & 27 & 0.05 \\
\hline 25 & Changureh, Iran-2002 & Reverse & 6.0 & 28 & 0.43 \\
\hline 26 & Changureh, Iran-2002 & Reverse & 6.0 & 28 & 0.44 \\
\hline 27 & Bam, Iran-2003 & Strike slip & 6.5 & 56 & 0.16 \\
\hline 28 & Bam, Iran-2003 & Strike slip & 6.5 & 56 & 0.1 \\
\hline 29 & Baladeh, Iran-2004 & Reverse & 6.3 & 20 & 0.29 \\
\hline 30 & Baladeh, Iran-2004 & Reverse & 6.3 & 20 & 0.16 \\
\hline
\end{tabular}




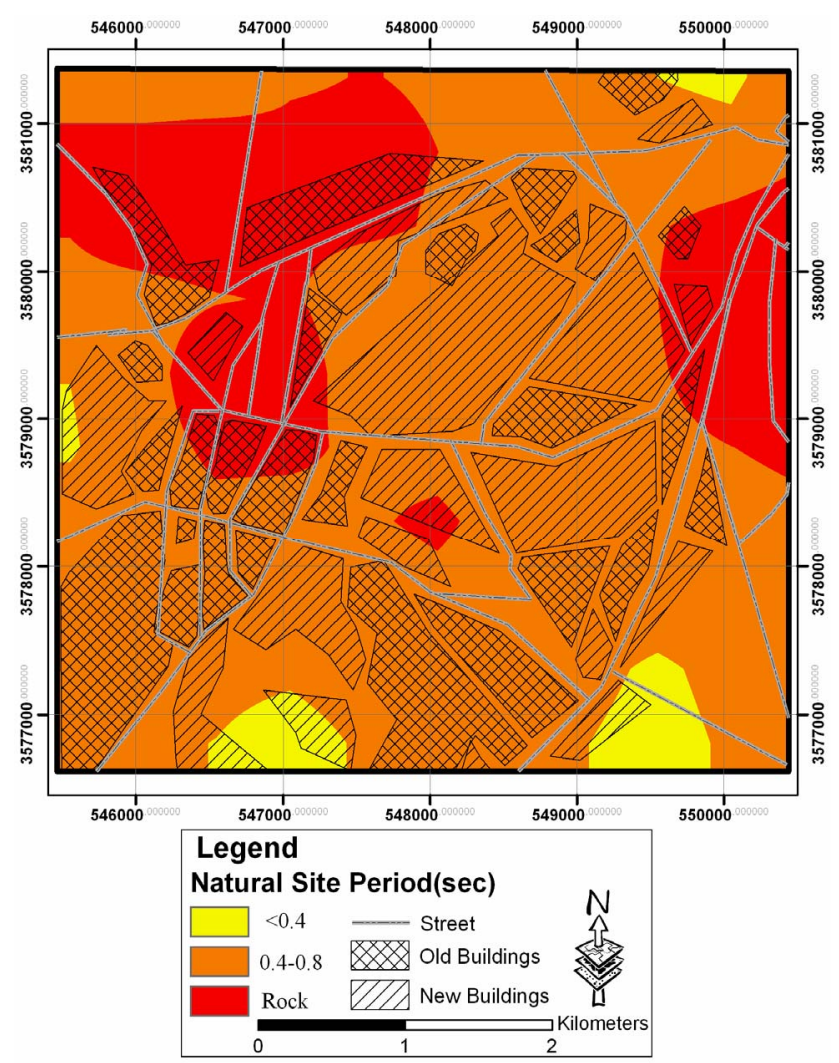

Figure 13. Distribution of TN through out Mobarakeh.

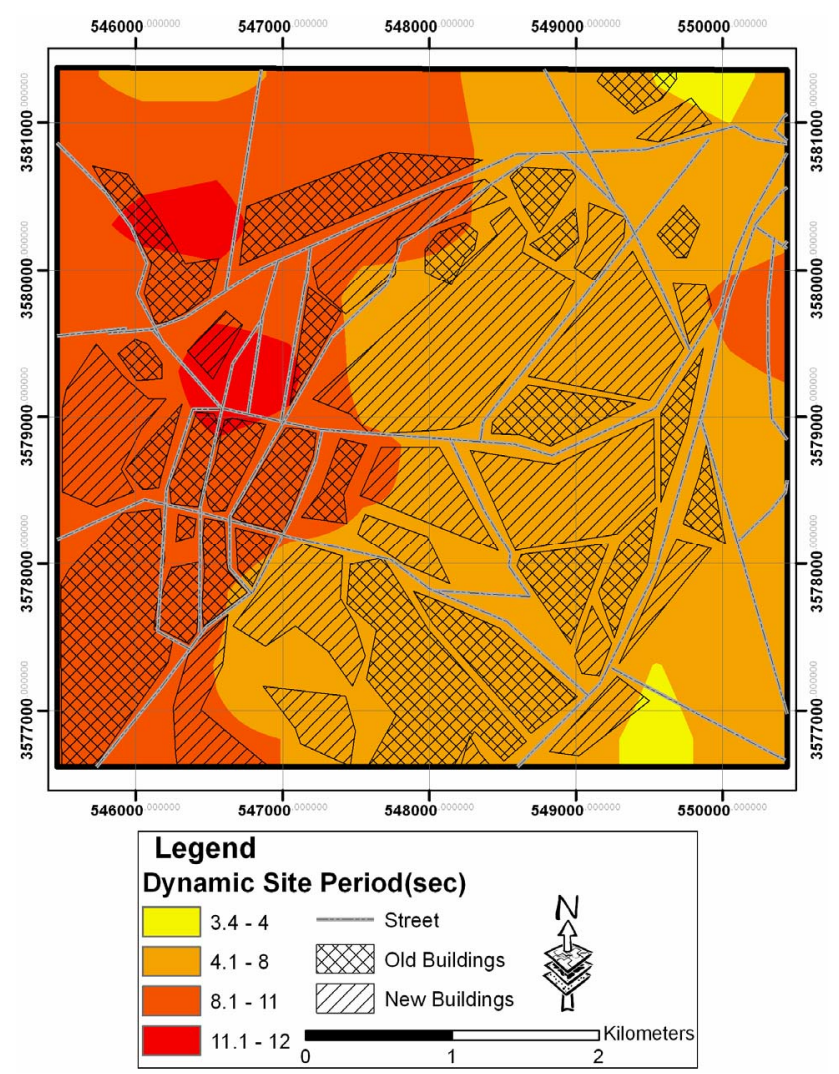

Figure 14. Distribution of TD through out Mobarakeh a return period of 475 years. 


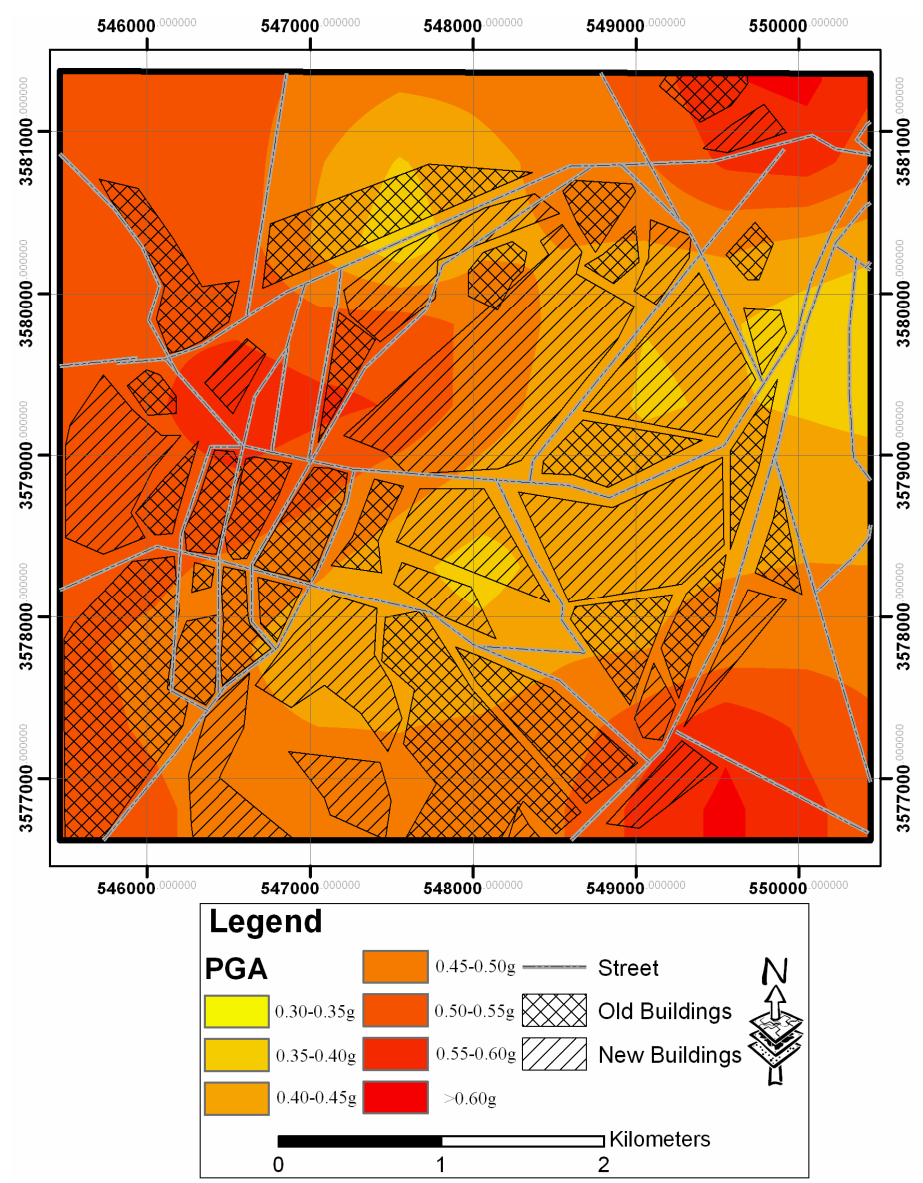

Figure 15. Distribution of PGA through out the city for a return period of 475 years.

city, estimated 475 year PGA values are higher than the maximum Design Base Acceleration (DBA) of $0.35 \mathrm{~g}$ proposed by the Iranian code for regions with very high levels of seismicity. This emphasizes once again the important role that site effect microzonation can play in seismic risk mitigation of seismic-prone zones. The microzonation maps of the natural site period, dynamic site period and PGA can be useful in land-use planning in consideration of population density, building height and building importance. It is obvious that more accurate evaluations of ground motion characteristics in the future require more geotechnical and geophysical data as well as consideration of the $3 \mathrm{D}$ effects of the surrounding mountain regions and of the sub-surface topography. It should also be noted that the microzonation maps are not intended to replace site-specific investigations for critical structures.

\section{REFERENCES}

[1] K. Rezaei, A. Friedrich, B. Guest, F. Fayazi, M. Nakhaei, S. M. F. Aghda and A. Beitollahi, "Soil and Sediment Quality and Composition as Factors in the Distribution of Damage at the December 26, 2003, Bam Area Earthquake in SE Iran $(M s=6.6)$," Journal of Soils and Sediments, Vol. 9, No. 1, 2009, pp. 23-32.

[2] M. Zare, “Contribution a L' Etude Des Movements Forts En Iran: Du Catalogue Aux Lois D' Attenuation,” Ph.D. Thesis, Joseph Fourier University, Grenoble, 1999.

[3] M. Kamalian, M. K. Jafari, M. R. Ghayamghamian, A. Shafiee, H. Hamzehloo, E. Haghshenas and A. SohrabiBidar, "Site Effect Microzonation of Qom, Iran," The Journal of Engineering Geology, Vol. 97, No. 1, 2008, pp. 63-79.

[4] K. Ishihara and A. M. Ansal, "Dynamic Behavior of Soil, Soil Amplification and Soil Structure Interaction," Final Report for Working Group D, UNDP/UNESCO Project on Earthquake Risk Reduction in the Balkan Region, 1982 .

[5] K. Rezaei, S. Norouzi and R. Sarraf, "Study of Relationship between Q and Electric Resistivity and Thickness (RT) in Aliabad Plain of Mobarakeh," The 1st Conference of Applied Geology in Iran, Azad University of Mashhad, Farsi, 2007.

[6] H. R. Ramazi, "Seismotectonic, Seismicity and Relative Earthquake Hazard Zoning in Mobarakeh Province," Housing and Urbanization Organization, Mobarakeh, 2002.

[7] D. M. Boore, W. B. Joyner and T. E. Fumal, "Equations for Estimating Horizontal Response Spectra and Peak 
Acceleration from Western North American Earthquakes: A Summary of Recent Work," Seismological Research Letters, Vol. 68, No. 1, 1997, pp. 128-153. doi:10.1785/gssrl.68.1.128

[8] K. W. Campbell and Y. Bozorgnia, "Updated Near-Source Ground-Motion (Attenuation) Relations for the Horizontal and Vertical Components of Peak Ground Acceleration and Acceleration Response Spectra," Bulletin of the Seismological Society of America, Vol. 93, No. 1, 2003, pp. 314-331. doi:10.1785/0120020029

[9] International Council of Building Officials, "Uniform Building Code. International Council of Building Officials," International Building Code, 1997.

[10] Building Seismic Safety Council, "NEHRP Recommended Provisions for Seismic Regulations for New Buildings and Other Structures, Part 1: Provisions (FEMA368)," Federal Emergency Management Agency, Oklahoma City, 2003.

[11] Building and Housing Research Center, "Iranian Code of Practice for Seismic Resistant Design of Buildings, Standard No. 2800," 3rd Edition, Building and Housing Research Center, Tehran, 2005.

[12] P. B. Schnabel, J. Lysmer and H. B Seed, "Shake: A Computer Program for Earthquake Response Analysis of
Horizontally Layered Sites," Report EERC-72-12, Earthquake Engineering Research Center, University of California, Berkeley, 1972.

[13] H. B. Seed and I. M. Idriss, "Soil Moduli and Damping Factors for Dynamic Response Analysis," Report EERC7010,1970 .

[14] Geological Survey of Iran, "Geological Map of Iran, 1:100,000 Series, Sheet 6169-Esfahan,” 1978.

[15] Water Affairs Office of Mobarakeh Province (WAO-QP), "Location Map of Water Wells and Ground Water Level Maps of Mobarakeh Area," Water Resources Assessment Office, Ministry of Power (WRAO-PM), Geo Electrical Studies of Mobarakeh Region, 2004.

[16] K. Hessami, F. Jamali and H. Abasi, "Major Active Faults of Iran," International Institute of Earthquake Engineering and Seismology (IIEES), 2003.

[17] Technical Committee for Earthquake Geotechnical Engineering "Revised Manual for Zonation on Seismic Geotechnical Hazards," Japanese Society of Soil Mechanics and Foundation Engineering, 1999.

[18] Earthquake Engineering Research Center, "Technical Committee for Earthquake Geotechnical Engineering, (TC4)," University of California, Berkeley, 1999. 